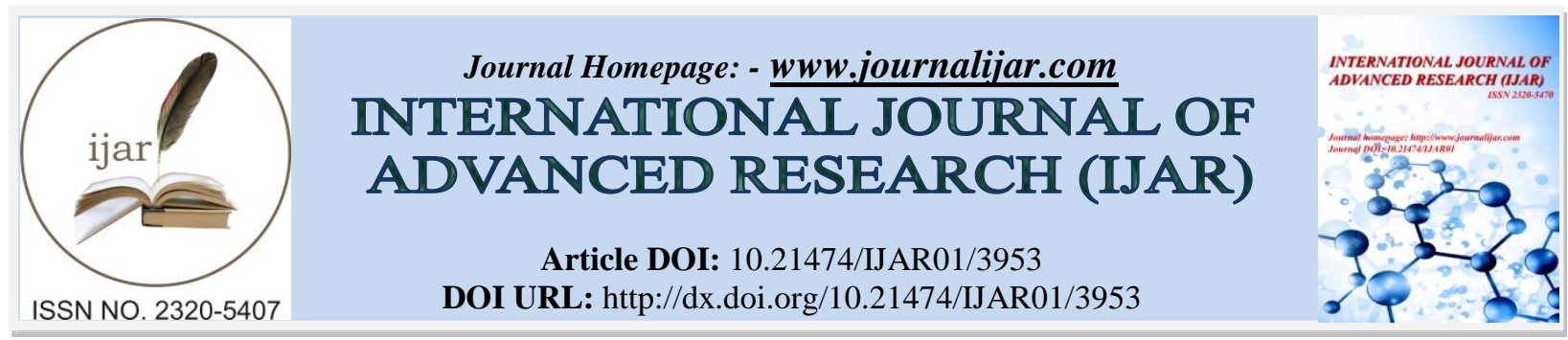

RESEARCH ARTICLE

\title{
MAPPING OF ZONES AT RISK (ZAR) IN WEST AFRICABY USING NGI, VCI AND SNDVI FROM THE
} E-STATION.

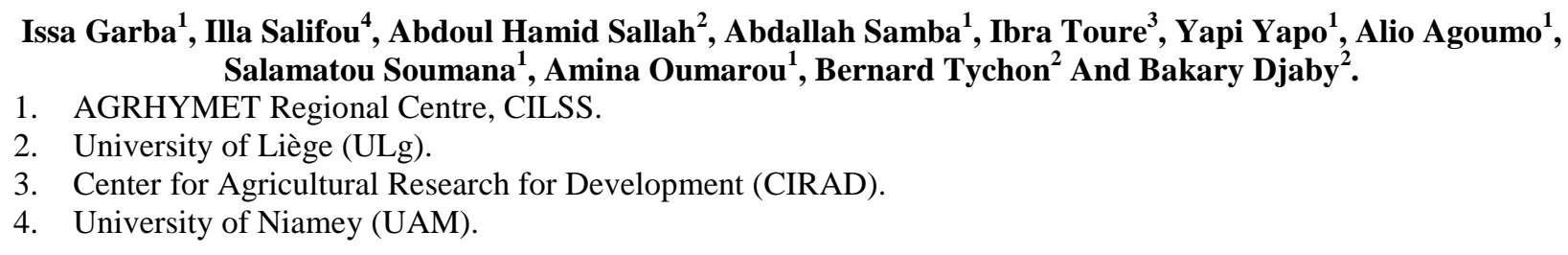

\section{Manuscript Info}

Manuscript History

Received: 18 February 2017

Final Accepted: 16 March 2017

Published: April 2017

Key words:-

AMESD, MESA, VCI, NGI, SNDVI, DROUGHT, AGRHYMET, CILSS.

\begin{abstract}
This work is carried out at the AGRHYMET Regional Centre (ARC)CILSS as part of the African Monitoring of Environment for Sustainable Development (AMESD) project. The analysis protocol has been improved under the Monitoring of Environment for Security in Africa (MESA) project. The MESA Project has been designed on the achievements of AMESD; its overall objective is to provide African countries with access to Earth Observation data for environmental monitoring and sustainable development. The specific objective of this study is to develop an operational analysis protocol for vegetation monitoring in general and especially for crops and pastures. Three vegetation indices were used: Vegetation Condition Index (VCI), Normalized Growth Index (NGI) and Standardized Normalized Difference Vegetation Index (SNDVI). The analysis of these drought indices is based on taking into account the agro-climatic characteristics of the Sahelian region, the comparison of the NGI profile (per administrative unit) from year $X$ (in progress) to the maximum NGI profiles, minimum and average of the time series data (1998 to year $\mathrm{x}$ 1) and evidence convergence. Six years of application of the method and validation actions carried out concluded that it is possible to determine the zones at risk (ZAR) in order to anticipate food crises.
\end{abstract}

Copy Right, IJAR, 2017,. All rights reserved.

\section{Introduction:-}

In the Sahel, the success of the agricultural season depends, at a large extent, to rain-fed crop productions, which in turn depends mainly on the quantity and regularity of rainfall (1). Crops can produce only if they have been able to complete their cycle, namely vegetative phase and reproductive phase, which minimum duration is estimated to 70 days for short-cycle varieties. In addition, the cycle must be able to be carried out under conditions that are favorable to plant development which means a sufficient moisture condition in the soil to satisfy the crop water requirement. The Favorable Crop Growth Period (FCGP) is the period when soil moisture conditions can meet the water requirements of rain-fed crops. In order to produce, the plants must therefore benefit from a FCGP of at least 70 days. The date of the first successful seeding determines the beginning of the FCGP: it varies enormously from one area to another and from year to year. In the Sahel, the further northward, the greater the variability (2). The date on 
which the soil moisture level falls below the minimum values necessary for plant growth determines the end of the FCGP. It varies much less than the start date, the standard deviation of the end date of the rainy season is about half that of the start date (3-5). The crop installation phase takes place during the first part of the rainy season, which is most exposed to atmospheric conditions. The catastrophic droughts that have hit the Sahel in recent decades have been largely determined either by a delay in the onset of the rains or a prolonged rainfall in the early phases of the rainy season. Crops are fairly sensitive to drought during the early stages of growth. Sahelian peasants sow rain-fed crops (millet, sorghum, groundnuts, cowpeas, etc.) at the first useful rainfall, that is to say, the rainfall that wets sufficiently the soil to allow seed germination. In most parts of the Sahel, rainfall exceeding $20 \mathrm{~mm}$ is sufficient to sow $(5,6)$. The immediate aftermath is rather tricky for rain-fed crops and, at this stage, prolonged drought can cause seedling death and oblige farmers to sow again. Therefore, if the crop is properly installed, the duration of the FCGP is likely to be sufficient to meet the water requirements of rain-fed crops and to ensure agricultural production. On the other hand, if the installation phase is unfavorable, there is a good chance that the duration of the FCGP will not be sufficient for the crops to be produced in good conditions. The analysis of the rain-fed crop installation phase aims to identify as soon as possible the areas in which the agricultural production is in danger because the crop installation phase did not proceed in good conditions. This information is very useful for early warning systems that are responsible for monitoring the food situation in the Sahelian countries, as population feeding is largely dependent on local agricultural production, especially in the poorest areas. For this reason we are trying to characterize the wintering profile from August onwards, so as to give decision-makers the possibility of activating the mechanisms of reaction to food crises in time. Crops are fairly sensitive to drought during the early stages of growth. The varieties of cereals (in particular millet) grown in the Sahelian strip are mostly photoperiodic, that is to say they move to the reproductive phase when the day's duration falls below a precise threshold; almost completely independent on the duration of the vegetative phase. Therefore, if it has been too short, the yield will be heavily affected and, in the worst case, it will be null. On the other hand, an extension of the rainy season beyond the normal date will have no effect on the biological behavior of the crops. In this study, we used the 1998 to 2011 image series of standardized difference vegetation index (NDVI) from SPOT VEGETATION and PROBA_V. These are spatial resolution images received in the AMESD station via the EUMETCAST network. Over the past 40 years, NDVI images have been extensively used to monitor vegetation phenology or other landscape changes (7-9). For heterogeneous soil cover, NDVI is normally higher in areas with a more favorable climate, soil and more productive ecosystems (forest) than in areas where environmental conditions are less favorable (dry steppe) (10-15). They are appreciated all over the world. In spite of its potential, many imperfections have been indicated: effects of the ground background, cloud contamination, dust, water vapor (16-25).To reflect the characteristics of the ecosystems and separate the meteorological signal from the ecological signal, the NDVI has been transformed into a Vegetation Condition Index (VCI) (26-30). The Vegetation Status Index (VCI and NGI) is the ratio of NDVI collected on a Period and its maximum historical deviation (maximum minus the minimum) obtained from data series of several years. The minimum and maximum values of NDVI are related to the ecological characteristics of each zone (31-35): the historical maximum is related to the geographical resources of each zone (climate, soil, vegetation); the historical minimum defines the threshold at which vegetation starts its growth and is related to the type of vegetation cover of each zone. The possible values for VCI and NGI are between 1 and 100, VCI values below or equal 35 indicate drought (32). It is important to note that in the event of prolonged cloud periods, NDVI values tend to decrease, giving a false impression of drought. The overall objective of this work is to use these indices to monitor and qualitatively forecast crop production in West Africa. More specifically, it is necessary to determine the zones at risk (ZAR) through the identification of zones favorable or unfavorable to a good production, combining mainly the VCI, the NGI and the SNDVI (36)

\section{Equipment and methods:- \\ Equipment:- Acquisition system of data used:}

The e-station allows acquisition, automated data processing and distribution of products by EUMETCAST and the internet. These earth observation data can be displayed and interpreted by technicians in charge of environmental monitoring, crop monitoring, pastures, water bodies, etc. The analysis of the vegetation state permits to produce warning and information bulletins that contribute to the decision-making (figure1). 

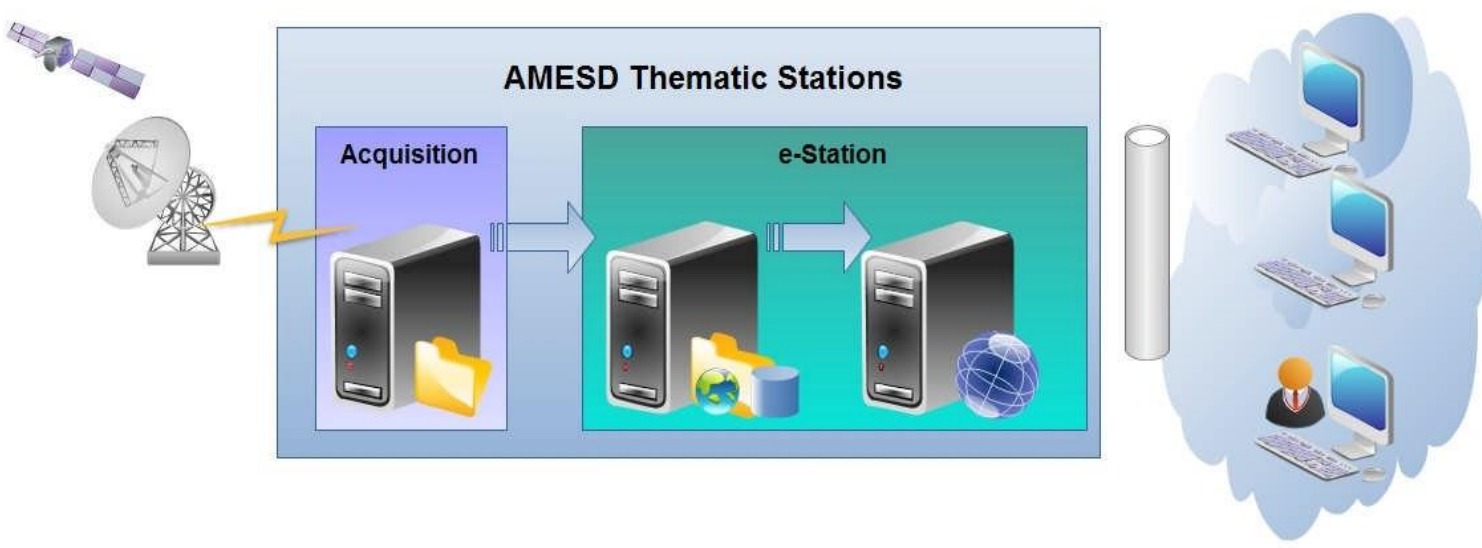

Figure1:- Acquisition and data processing system

\section{Images used:}

As part of the implementation of the analysis protocol, the following vegetation indices are mainly used:

\section{Vegetation Condition Index (VCI):-}

Historical minimum and maximum values are calculated separately for each decade from the historical image series (34). This vegetation index version shows the vegetation conditions in each zone at any time during the rainy season:

$\mathrm{VCI}=\left(\mathrm{NDVI} \_\mathrm{x}-\mathrm{NDVImin} \_\mathrm{x}\right) /($ NDVImax_x - NDVImin_x $) * 100$ where NDVI_x is the NDVI for the current decade $x$, when NDVImin_x and NDVImax_x are the maximum and minimum historical NDVI value for the same decade. (Figure. 2).

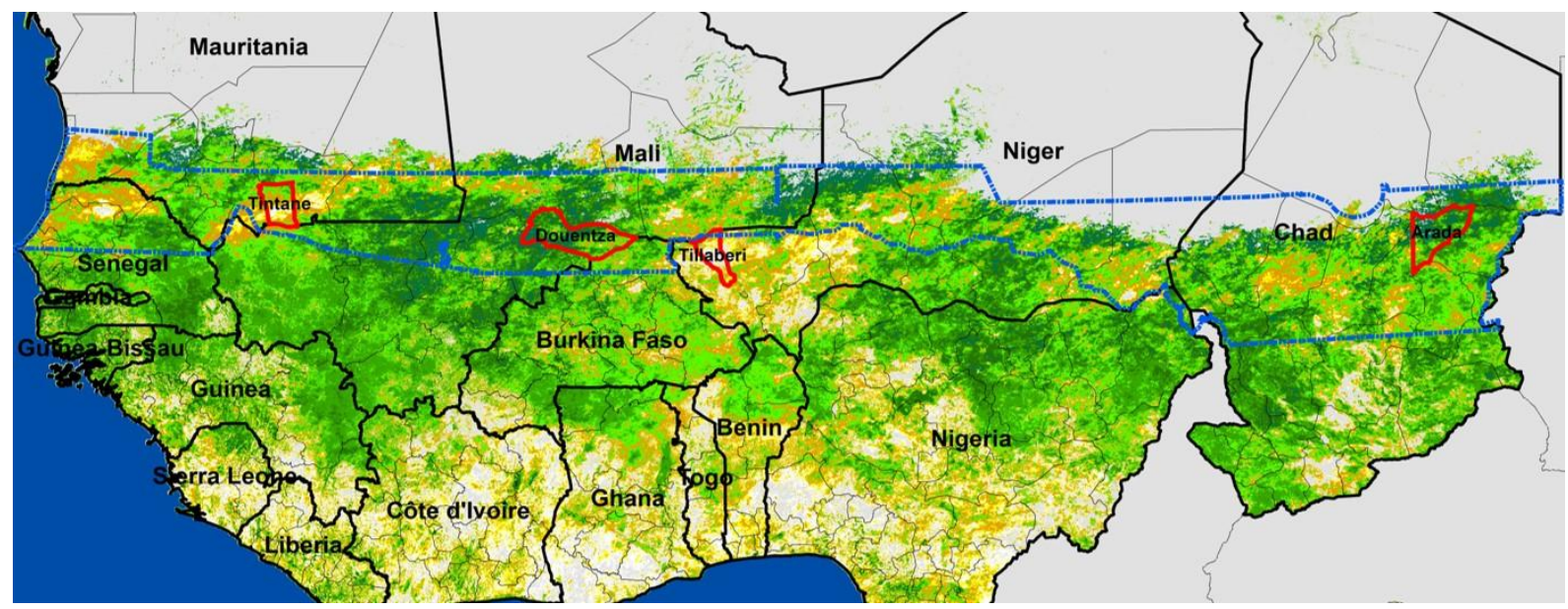

\section{Vegetation Condition Index (VCl)}
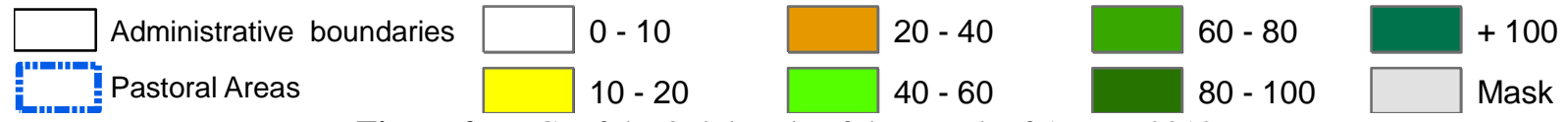

Figure 2:- VCI of the 3rd decade of the month of August 2012 


\section{Normalized Growth Index (NGI):-}

Historical maximum and minimum values are calculated for the entire season, from May to October, on the series of historical images (37); this version of vegetation index is better suited for: a) visualizing the spatial response from vegetation to precipitation, $b$ ) monitoring the vegetation growth progress over time through the creation of temporal profiles of the index (Figure3).

NGI=(NDVI_x-NDVImin)/(NDVImax-NDVImin)*100

Where NDVI_x is the NDVI of the present decade $x$, when NDVImin and NDVImax are the absolute maximum and minimum for the entire growing season of the vegetation (May-October)

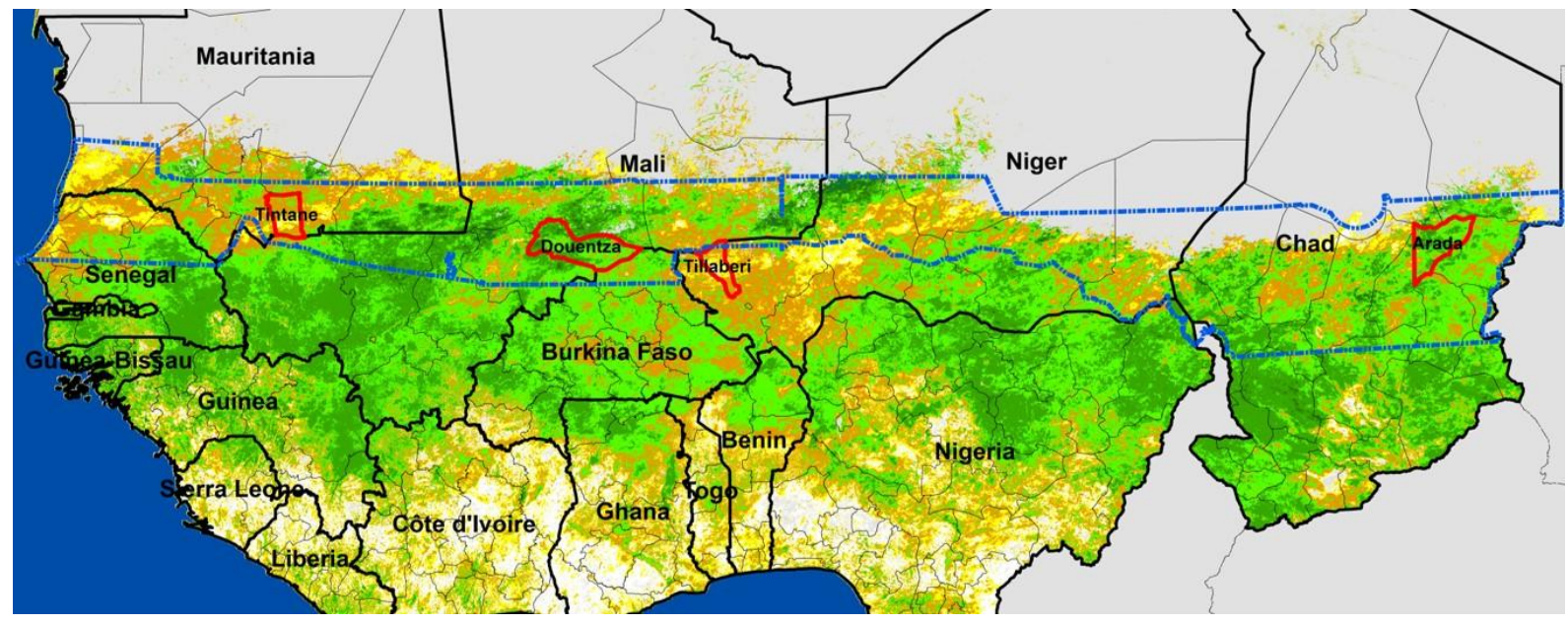

Normalized Growth Index ( NGI)

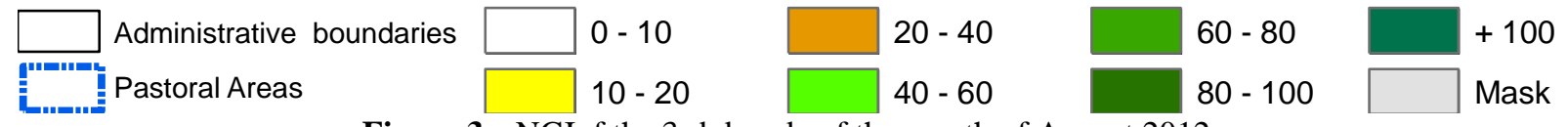

Figure 3:- NGIof the 3rd decade of the month of August 2012

\section{Standardized NDVI:-}

SNDVI=(NDVI_x-NDVImoy_x)/Standarddeviation_x

Where NDVI_xis the NDVI image of the current decade X when NDVImoy_x and Standard Deviation_x are the statistical images of NDVI for the same decade X.

In our case, for a given pixel, the value of the standard deviation can be calculated; the difference between the NDVI value of a given decade and the mean value divided by the value of the standard deviation gives a value which can theoretically vary between $-\infty$ and $+\infty$ but which, in the great majority of cases, distributes between -4 and +4 . (Figure 4) 

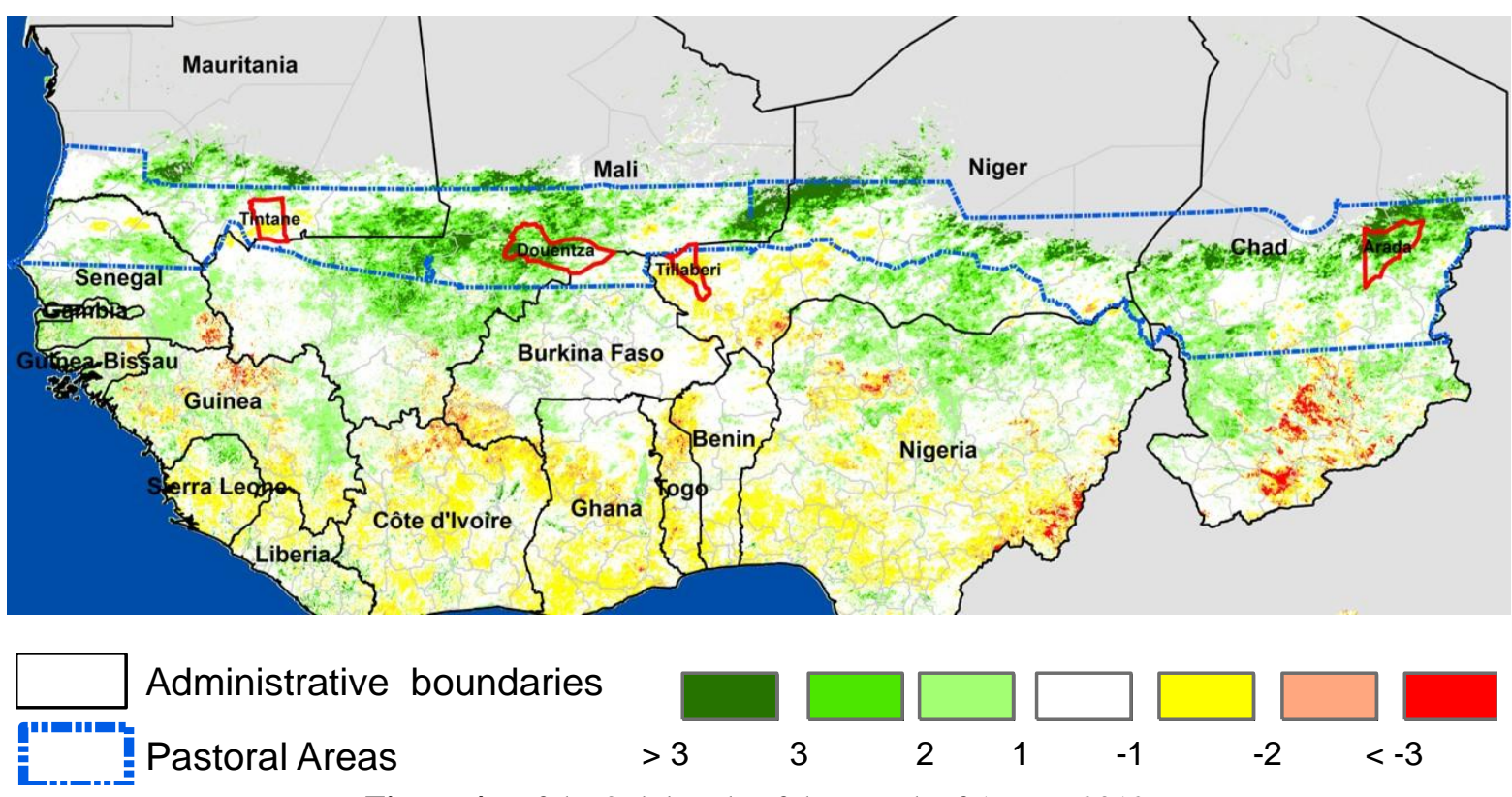

Figure 4:- of the 3rd decade of the month of August 2012

\section{Analysis method:-}

Vegetation growth analysis:-

The VCI expresses, in percentage, the growth level reached by the vegetation at a given date in relation to the maximum level reached before the same date. It permits to compare the growth level of the vegetation between zones that are characterized by a different ecological potential. The NGI is more effective than the VCI for designing vegetation growth time profiles. In this work: the NGI time profiles are designed for all administrative units; we calculate the average value (of the NGI) as for the pixels of the administrative unit; we can isolate pixels where rain-fed crop is dominant; Finally, for each administrative unit, we design profiles of the minimum, maximum and average values of the NGI (period 1998-2011).

\section{NGI temporal profiles Analysis:-}

For each decade, the average NGI values are calculated for each administrative unit in each country. These values are represented on graphs which permit to monitor the vegetation growth over time. On the same charts, there are historical reference values (maximum, minimum, average values, previous year) which permit to better characterize the progress of the current campaign. In the graph for the NGI of the region, the effect of growth anomalies on the current season (2012) can easily be seen. NGI profiles are also useful in determining whether the vegetation growth level within an administrative unit is homogeneous or, on the contrary, there are contrasting situations. In the Sahel even in normal or favorable years, due to the spatial and temporal variability of precipitation, there may be pockets of agricultural production deficient due to localized droughts. The comparison of the different administrative units' profiles on the same graph permits to easily identify risk areas (Figure 5).
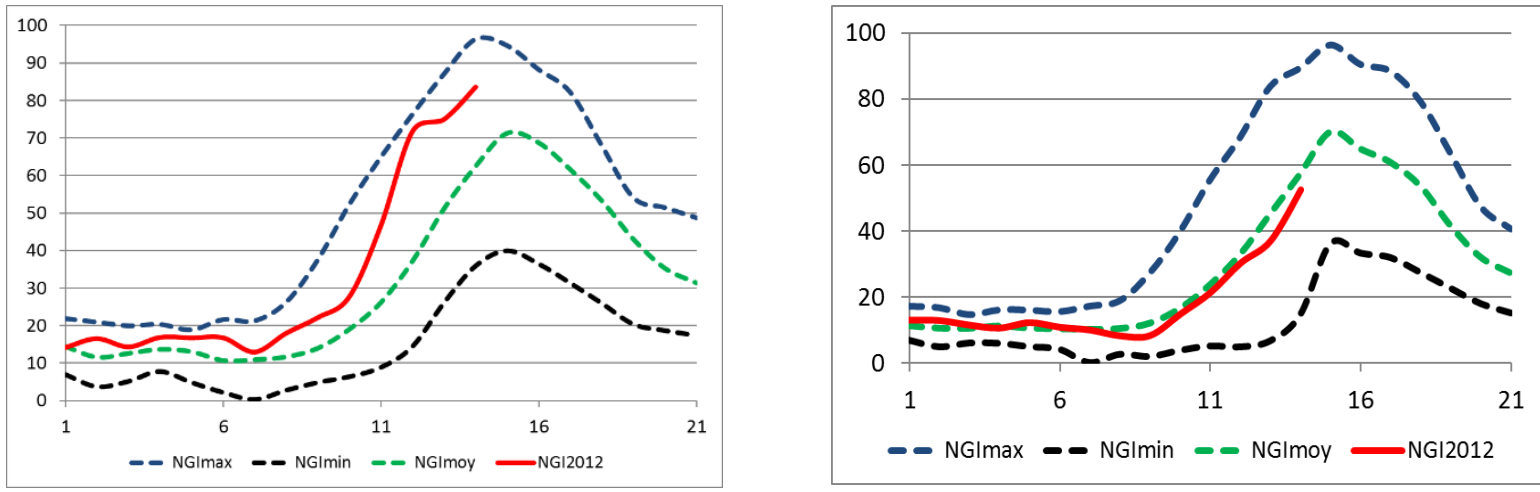


\section{Profile: NGIDouentza (Mali)}

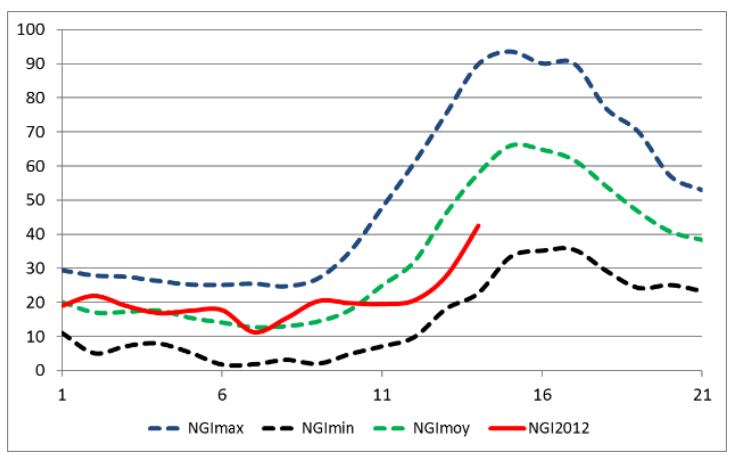

Profile: NGITillabery (Niger)
Profile: NGITitane (Mauritania)

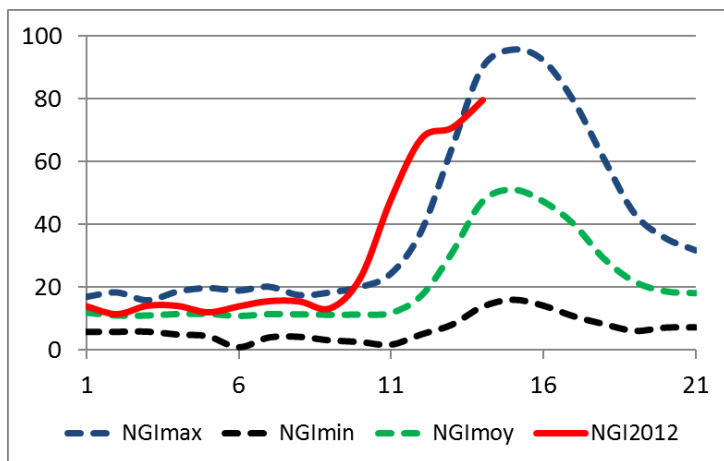

Profile: NGIArada(Chad)

Figure5:- NGIprofiles compared to historic references for Douentza (Mali), Titane (Mauritania), Tillabery (Niger) and Arada (Chad).

\section{Combined analysis of images:-}

A classification is made either manually through a visual interpretation or by simple clustering of the difference of the NGI images of the current year with respect to the average of the time series. Then, the VCI images are checked for the conformity and persistence of vegetation growth conditions in the different classes namelyfavorable, unfavorable or normal conditions. These identified areas are then crossed with SNDVI images (growth anomaly compared to the average of the series). In case of divergence of evidence, the distribution of estimated rainfall by satellite is examined to ascertain the regularity and the quantity recorded following the decades

\section{Results:-}

The combination of the three vegetation indices (NGI, VCI, SNDVI and the NGI profiles at the administrative unit level) permits to produce a synthetic map on crop and pasture status at the beginning of mid-August(Figure6). This map of areas favorable or unfavorable to good crop production is generally updated in October to establish a final assessment of the agro-pastoral campaign.

- Red: shows areas with an unfavorable situation. That is, areas where rainfall conditions have not been conducive to good growth and significant growth of vegetation, suggesting very poor prospects for agropastoral production. These are the areas where either a long delay of more than a month in the planting of crops has been recorded or a long rainfall pause has led to the loss of the first seedlings;

* White is related to medium-sized areas as compared to the average recorded over the last 14 years. We can expect agro-pastoral production at least equal to the period average; The greens represent the zones with favorable situation and even very favorable. That is, areas where rainfall conditions have allowed good growth and favorable vegetation development, suggesting good to very good agro-pastoral production;

* The green represents the zones with favorable situation and even very favorable. That is, areas where rainfall conditions have allowed good growth and favorable vegetation development, suggesting good to very good agro-pastoral production. 


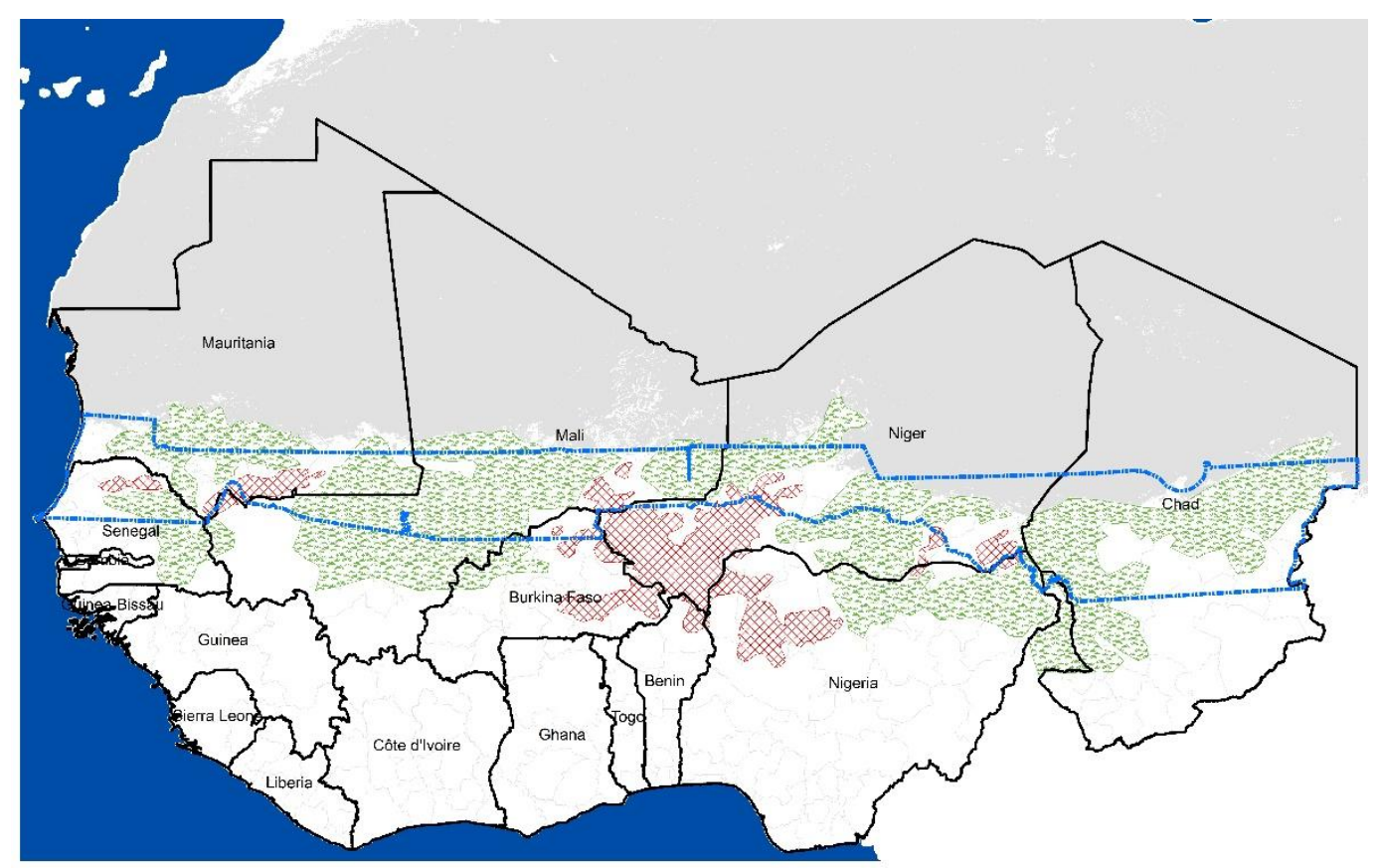

Unfavorabe condition Normal condition Favorable condition

Pastoral area

Administrative boundaries

Figure 6:- Summary map of the regional status of crop and pasture conditions in mid-August 2012 (Zones at Risk)

Despite the abundant rains of recent weeks, there has been a poor installation of the first phase of the 2012/2013 agro-pastoral campaign, notably: in Niger in the regions of Tahoua, Dosso and Tillabéry, somewhat in the Diffa region; In Burkina in the eastern, central and Sahel regions; In Mali, somewhat in border areas in Niger; Senegal north of Matam and east of Louga; In Mauritania in the regions of Assaba, Guidimahka and HodhEchGharbi. This unfavorable situation results from a significant delay in sowing or loss due to either a lack of useful rainfall or a prolonged rainfall pause. Whatever the conditions of the second phase of the agro-pastoral campaign, a drop in production is feared in these areas, especially for photoperiodic species. There is also an above-average vegetative growth (favorable condition) in the central regions of Niger (Maradi and Zinder), in Mali in the central regions; throughout the Sahelian part of Chad; in Eastern Senegal and the Pastoral Center of Mauritania. If this trend continues, good harvests can be expected in these areas. In most areas, the situation remains normal.

\section{Validation of the map of zones at risk in Niger (August 2012):-}

After the mapping work, it is important to go to the field to collect data and to cross the results obtained. It was found that the information recorded on the map conforms to that collected on the ground (Figure 7). 


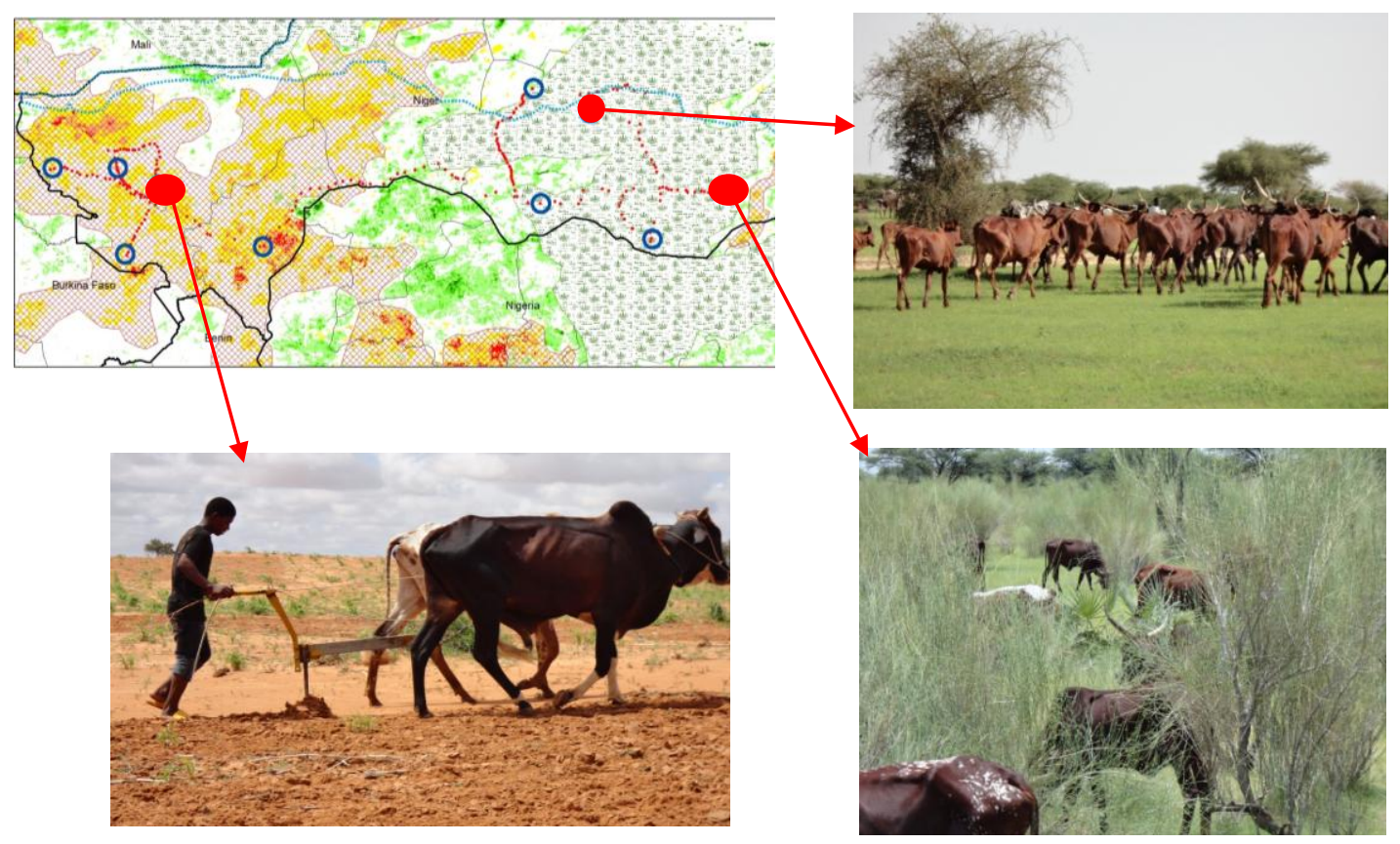

Figure 7:- validation of the zone at risk map in Niger in 2012

\section{Conclusion:-}

The combination of the NGI, VCI and SNDVI vegetation indices permits to make a qualitative forecast of crop production. By detecting areas at risk in time, we can anticipate food crises. This information is very useful for early warning systems that are responsible for monitoring the food situation in the Sahelian countries, as population feeding is largely dependent on local agricultural production, especially in the poorest areas. The possibility of characterizing the wintering profile from August onwards, so as to give decision-makers the possibility of activating the mechanisms of reaction to food crises in a timely manner, constitutes an appreciable contribution of remote sensing.

\section{References:-}

1. Mahaman K. , Barage M, Balla A, Adam T, \& Yamba B (2011) Influence des fluctuations pluviométriques sur la saison agricole dans la zone géographique de Mayahi et Aguié au Niger.

2. Diop M (1996) A propos de la durée de la saison des pluies au Sénégal. Science et changements planétaires/Sécheresse 7(1):7-15.

3. Sivakumar MVK (1988) Predicting rainy season potential from the onset of rains in Southern Sahelian and Sudanian climatic zones of West Africa. Agricultural and Forest Meteorology 42(4):295-305.

4. Sivakumar MVK, Maidoukia A, \& Stern RD (Agroclimatology of west africa: Niger.

5. Sivakumar MVK (1990) Exploiting rainy season potential from the onset of rains in the Sahelian zone of West Africa. Agricultural and Forest Meteorology 51(3-4):321-332.

6. Gueye M \& Sivakumar MVK (1992) Analyse de la longueur de la saison culturale en fonction de la date de début des pluies au Sénégal. Compte rendu des travaux (2).

7. Al-Bakri JT \& Taylor JC (2003) Application of NOAA AVHRR for monitoring vegetation conditions and biomass in Jordan. Journal of Arid Environments 54(3):579-593.

8. Anyamba A \& Tucker CJ (2005) Analysis of Sahelian vegetation dynamics using NOAA-AVHRR NDVI data from 1981-2003. Journal of Arid Environments 63(3):596-614.

9. Azzali S \& Menenti M (1996) Fourier analysis of time series of NOAA-AVHRR NDVI monthly composites for monitoring vegetation-soil-climate complexes in Southern Africa. Fourier Analysis of Temporal NDVI in the Southern African and American Continents. Rep 108:37-81.

10. Defries RS \& Townshend JRG (1994) NDVI-derived land cover classifications at a global scale. International Journal of Remote Sensing 15(17):3567-3586. 
11. Fensholt R \& Sandholt I (2004) Evaluating MODIS TERRA and SPOT-4 VEGETATION 10-day composite NDVI values against in situ measured NDVI (2001-2003) in the semi-arid Senegal. 35th COSPAR Scientific Assembly. Held 18 - 25 July 2004, in Paris, France.:1979.

12. Griffith JA, Martinko EA, Whistler JL, \& Price KP (2002) Interrelationships among Landscapes, NDVI, and Stream Water Quality in the U.S. Central Plains. Ecological Applications 12(6):1702-1718.

13. Lloret F, et al. (2007) Woody Plant Richness and NDVI Response to Drought Events in Catalonian (Northeastern Spain) Forests. Ecology 88(9):2270-2279.

14. Zhang L, Chen X, Cai X, \& Salim H (2010) Spatial-temporal changes of NDVI and their relations with precipitation and temperature in Yangtze River basin from 1981 to 2001. Geo-spatial Information Science 13(3):186-190.

15. Zhan Z-Z, Liu H-B, Li H-M, Wu W, \& Zhong B (2012) The Relationship between NDVI and Terrain Factors -A Case Study of Chongqing. Procedia Environmental Sciences 12, Part B:765-771.

16. Eklundh L \& Singh A (1993) A comparative analysis of standardised and unstandardised Principal Components Analysis in remote sensing. International Journal of Remote Sensing 14(7):1359-1370.

17. Eklundh LR (1995) Noise estimation in NOAA AVHRR maximum-value composite NDVI images. International Journal of Remote Sensing 16(15):2955-2962.

18. Karabulut M (2003) An examination of relationships between vegetation and rainfall using maximum value composite AVHRR-NDVI data. Turkish Journal of Botany 27(2):93-101.

19. Marcal ARS \& Wright GG (1997) The use of 'overlapping' NOAA-AVHRR NDVI maximum value composites for Scotland and initial comparisons with the land cover census on a Scottish Regional and District basis. International Journal of Remote Sensing 18(3):491-503.

20. Seaquist JW, Chappell A, \& Eklundh L (2002) Exploring and improving NOAA AVHRR NDVI image quality for African drylands. Geoscience and Remote Sensing Symposium, 2002. IGARSS '02. 2002 IEEE International 4:2006-2008 vol.2004.

21. Fontana FMA, Trishchenko AP, Khlopenkov KV, Luo Y, \& Wunderle S (2009) Impact of orthorectification and spatial sampling on maximum NDVI composite data in mountain regions. Remote Sensing of Environment 113(12):2701-2712.

22. Holben BN (1986) Characteristics of maximum-value composite images from temporal AVHRR data. International Journal of Remote Sensing 7(11):1417-1434.

23. Chen PY, Fedosejevs G, Tiscareno-Lopez M, \& Arnold JG (2006) Assessment of MODIS-EVI, MODIS-NDVI and VEGETATION-NDVI composite data using agricultural measurements: an example at corn fields in western Mexico. Environ Monit Assess 119(1-3):69-82.

24. Budde ME, Tappan G, Rowland J, Lewis J, \& Tieszen LL (2004) Assessing land cover performance in Senegal, West Africa using 1-km integrated NDVI and local variance analysis. Land Cover, Biomass and Soil Carbon Trends in Senegal: Mnagemnet Options and Climate Sensitivity 59(3):481-498.

25. Maxwell SK \& Sylvester KM (2012) Identification of "ever-cropped" land (1984-2010) using Landsat annual maximum NDVI image composites: Southwestern Kansas case study. Remote Sensing of Environment 121(0):186-195.

26. Domenikiotis C, Spiliotopoulos M, Tsiros E, \& Dalezios NR (2004) Early cotton production assessment in Greece based on a combination of the drought Vegetation Condition Index (VCI) and the Bhalme and Mooley Drought Index (BMDI). International Journal of Remote Sensing 25(23):5373-5388.

27. Qi S, Wang C, Niu Z, \& Liu Z (2004) SVI and VCI Based on NDVI Time-Series Dataset Used to Monitor Vegetation Growth Status and Its Response to Climate Variables [J]. Progress In Geography 3.

28. Quiring SM \& Ganesh S (2010) Evaluating the utility of the Vegetation Condition Index (VCI) for monitoring meteorological drought in Texas. Agricultural and Forest Meteorology 150(3):330-339.

29. Unganai LS \& Kogan FN (1998) Drought monitoring and corn yield estimation in Southern Africa from AVHRR data. Remote Sensing of Environment 63(3):219-232.

30. Unganai LS \& Kogan FN (1998) Southern Africa's recent droughts from space. Remote Sensing: Inversion Problems and Natural Hazards 21(3):507-511.

31. Kogan FN (1990) Remote sensing of weather impacts on vegetation in non-homogeneous areas. International Journal of Remote Sensing 11(8):1405-1419.

32. Kogan FN (1995) Application of vegetation index and brightness temperature for drought detection. Advances in Space Research 15(11):91-100.

33. Liu WT \& Kogan FN (1996) Monitoring regional drought using the vegetation condition index. International Journal of Remote Sensing 17(14):2761-2782. 
34. Kogan FN (1997) Global drought watch from space. Bulletin of the American Meteorological Society 78(4):621-636.

35. Kogan F, et al. (2004) Derivation of pasture biomass in Mongolia from AVHRR-based vegetation health indices. International Journal of Remote Sensing 25(14):2889-2896.

36. Peters AJ, et al. (2002) Drought monitoring with NDVI-based standardized vegetation index. Photogrammetric Engineering and Remote Sensing 68(1):71-75.

37. Kogan F (1990) Remote sensing of weather impacts on vegetation in non-homogeneous areas. International Journal of Remote Sensing 11(8):1405-1419. 